Article

\title{
Biocompatibility and Antimicrobial Activity of Reynoutria elliptica Extract for Dental Application
}

\author{
Song-Yi Yang ${ }^{1}\left(\mathbb{D}\right.$ and Min-Kyung Kang ${ }^{2, *}$ \\ 1 Department and Research Institute of Dental Biomaterials and Bioengineering, \\ Yonsei University College of Dentistry, Seoul 03722, Korea; syyang88@yuhs.ac \\ 2 Department of Dental Hygiene, Hanseo University, Chungcheongnam-do 31962, Korea \\ * Correspondence: kmk0709@hanseo.ac.kr; Tel.: +82-41-660-1575
}

Received: 11 May 2020; Accepted: 24 May 2020; Published: 26 May 2020

check for updates

\begin{abstract}
This study was conducted to determine whether nature-derived Reynoutria elliptica extracts exhibit biocompatibility and antimicrobial effects against oral pathogens such as Streptococcus mutans and Candida albicans. Fine particles of Reynoutria elliptica extract were used to probe for biocompatibility and antimicrobial activity toward these pathogens, and results were evaluated with an MTT (3-[4,5-dimethylthiazol-2-yl]-2,5 diphenyl tetrazolium bromide) assay, spectrophotometric growth inhibitory assay, the total number of colony-forming units (CFU), an agar disk diffusion test, and scanning electron microscopy (SEM). In addition, UV/VIS spectroscopy was used to determine the levels of flavonoid and polyphenol in experimental solutions. Several experimental groups showed cell viability higher than $70 \%$, and the antimicrobial activity toward both S. mutans and C. albicans was significantly higher than was that seen for the control group. In CFU and agar disk diffusion tests with C. albicans, increases in the concentration of Reynoutria elliptica extract led to significantly increased antimicrobial effects. Additionally, SEM results showed that Reynoutria elliptica extract changed the morphology and density of S. mutans and C. albicans. The results of this research can be applied to the use of Reynoutria elliptica extracts for the development of oral products that are biologically friendly and can control oral diseases such as dental caries and candida-associated denture stomatitis.
\end{abstract}

Keywords: antibacterial; antifungal; cell viability; dental materials; Reynoutria elliptica extract; Streptococcus mutans; Candida albicans

\section{Introduction}

Since the mouth is in direct contact with the external environment, it is constantly invaded by various microbes and has an environment suitable for bacterial growth and proliferation, both nutritionally and physiologically [1,2]. There are many kinds of microbes in human saliva and soft and hard tissue, and there are approximately 500 species that cause diseases. Streptococcus mutans, Prevotella intermedia, Porphyromonas gingivalis, and Candida albicans are among these, and the activities of these microbes in the mouth cause various oral diseases such as tooth decay, periodontal disease, oral candidiasis, and inflammation of the mouth [3-6]. In particular, oral diseases such as dental caries and periodontal diseases tend to leave permanent damage once they occur, so prevention, treatment, and post-treatment care are clearly important [7-9]. Therefore, inhibition of the activity of these oral pathogens is significant in the prevention and treatment of oral diseases [10].

Streptococcus mutans contributes to the rigid attachment of insoluble glucans to the tooth surface through glucosyltransferase action [11,12]. Streptococcus mutans is also known to adhere to the tooth surface and cause biofilm formation, which breaks down sugars and starches to release acids that may lead to tooth caries [13]. Thus, to prevent tooth caries, the use of antimicrobial materials is required to suppress the growth of S. mutans or to inhibit the attachment of other bacteria [14-16]. In addition, 
C. albicans is a common cause of oral mucosal infections, in which resident microbes in the mouth cause disease in patients with weakened immune systems and attach to the oral epithelial tissue or dentures. This often results in opportunistic infection and oral candidiasis [17-19]. Antifungal treatments with topical agents or medications are often utilized to treat these oral diseases and improve oral hygiene [20-23].

Prevention of oral diseases requires control of the formation of biofilms in the oral environment. Prior studies have been conducted to prevent and treat oral diseases using chlorhexidine, sodium lauryl sulfate, triclosan; moreover, antibiotics such as ampicillin, erythromycin, and penicillin are widely used in the dental clinic to suppress microbial growth [24-28]. However, it is known that the continuous use of synthetic chemicals and antibiotics with conventional antimicrobial properties can cause side effects such as cytotoxicity and mutagenicity. These result from the accumulation of synthetic antibacterial substances and, in the case of excessive use of these substances, changes in oral microbial strains, and both normal microbial residents and pathogens can be eliminated in the oral cavity [29-31]. Therefore, other publications have reported that limited use of antifungal agents is required to maintain host health while controlling harmful microbial pathogens $[32,33]$.

Recently, many natural medicines, which have fewer side effects and offer the possibility of long-term use, have been evaluated to determine their antibacterial and anti-inflammatory potential [34-38]. Included among these is a large group of perennial plants in the Polygonaceae, which are used in East Asian medicine to promote blood circulation, relieve pain, treat diuretic and menstrual disorders, and alleviate respiratory problems. In addition, other prior studies have demonstrated that Reynoutria elliptica has excellent antimicrobial activity against Helicobacter pylori, and other studies indicated that it contained a growth inhibitor for S. mutans and thus explored its ability to prevent dental caries [39-43].

However, there have been no scientific studies on the biocompatibility and antimicrobial properties of various concentrations of these naturally derived Reynoutria elliptica extracts. Therefore, we discuss herein the potential use of the natural substance Reynoutria elliptica extract for application in antibacterial and antifungal oral products. The purpose of this study is to evaluate the biocompatibility using L929 fibroblast cells and determine the antimicrobial activity against S. mutans and C. albicans strains, and also to provide basic data on Reynoutria elliptica extracts with the use of component analysis. The null hypothesis of this study is that various concentrations of the Reynoutria elliptica extract will not exhibit significant biocompatibility or antimicrobial properties.

\section{Materials and Methods}

\subsection{Preparation of Reynoutria elliptica Extracts}

Reynoutria elliptica grown in North Gyeongsang province located in Korea was purchased from an herbal shop (Hanyakjae market, Seoul, Korea). Five hundred grams of Reynoutria elliptica was crushed, poured into $5 \mathrm{~L}$ of a $70 \%$ methanol solution, and extracted at room temperature $\left(25 \pm 1{ }^{\circ} \mathrm{C}\right)$ for 2 days. This extract solution was filtered through \#2 filter paper (Whatman, Maidstone, UK) and was then evaporated and concentrated with a vacuum evaporator (EYELA, Tokyo, Japan). To produce the dried solid form, concentrated Reynoutria elliptica extract was frozen at $-20^{\circ} \mathrm{C}$ for $12 \mathrm{~h}$ and then stored in a freeze dryer (Ilshin Lab Co., LTD, Gyeonggi-do, Korea) at $-55^{\circ} \mathrm{C}$ for $48 \mathrm{~h}$. The freeze dried Reynoutria elliptica extract was ground to a fine powder using a mortar and pestle. The resulting Reynoutria elliptica extract powder was stored in a desiccator at room temperature $\left(25 \pm 1^{\circ} \mathrm{C}\right)$ before subsequent testing.

\subsection{Preparation of Cells for Biocompatibility Tests}

L929 mouse fibroblast cells were chosen to determine the biocompatibility of the Reynoutria elliptica extract. The cells were cultured as a monolayer in 75 T-flasks (SPL Life Science, Gyeonggi-do, Korea), sub-cultured three times within a week at $37 \pm 1{ }^{\circ} \mathrm{C}$ in a humidified $5 \% \mathrm{CO}_{2}$ /air environment and maintained at the fifth passage. The cell culture medium used was RPMI 1640 (Gibco Laboratories, Grand Island, NY, USA) with 10\% (v/v) fetal bovine serum (Gibco Laboratories, Grand Island, NY, USA) 
and $1 \%$ antibiotic-antimycotic solution (Anti-Anti, Gibco Laboratories, Grand Island, NY, USA). Cells adhering to the flask were detached with a mixture of $0.05 \%$ Trypsin-EDTA (Trypsin-EDTA, Gibco Laboratories, Grand Island, NY, USA), incubated for $10 \mathrm{~min}$ at $37 \pm 1^{\circ} \mathrm{C}$, and used for cell inoculation. One hundred microliter of a cell suspension with $1 \times 10^{5}$ cells $/ \mathrm{mL}$ were then seeded in 96-well culture plate (Thermo Fisher Scientific Inc., Waltham, MA, USA) and incubated at $37 \pm 1{ }^{\circ} \mathrm{C}$ in a humidified $5 \% \mathrm{CO}_{2} /$ air environment for $24 \mathrm{~h}$ to enable attachment.

\subsection{Cell Viability Assay}

The Reynoutria elliptica extract powder was irradiated for $30 \mathrm{~min}$ under ultraviolet light to prevent contamination, and then sterilized Reynoutria elliptica extract powders were dispersed with varying concentrations. To prepare the experimental solution, Reynoutria elliptica extract powders were dissolved in RPMI 1640 cell culture medium to achieve concentrations of $50 \mu \mathrm{g} / \mathrm{mL}, 100 \mu \mathrm{g} / \mathrm{mL}$, $150 \mu \mathrm{g} / \mathrm{mL}$ and $200 \mu \mathrm{g} / \mathrm{mL}$, and these solutions were stored at $37 \pm 1{ }^{\circ} \mathrm{C}$ in a humidified $5 \% \mathrm{CO}_{2} /$ air environment for $24 \mathrm{~h}$ (in accordance with ISO standard 10993-12). In addition, RPMI 1640 cell culture medium that did not contain Reynoutria elliptica extract was also stored as described above to establish a negative control for cell viability tests.

A test for in vitro cytotoxicity, the MTT assay, was performed according to ISO 10993-5. The culture medium in the 96-well plate was removed from the wells, and $100 \mu \mathrm{L}$ of the experimental and control solution was added into the each well. The plates were further incubated for $24 \mathrm{~h}$, and the test and control solutions were removed. Then, each well was washed with $100 \mu \mathrm{L}$ of pre-warmed Dulbecco's phosphate-buffered saline solution (D-PBS, Gibco Laboratories, Grand Island, NY, USA). The D-PBS was removed, and the wells were refilled with $50 \mu \mathrm{L}$ of $1 \mathrm{mg} / \mathrm{mL}$ MTT-tetrazolium salts (Sigma-Aldrich, St. Louis, MO, USA) in PBS and the plates were kept at $37 \pm 1{ }^{\circ} \mathrm{C}$ in a humidified $5 \% \mathrm{CO}_{2} /$ air environment for $2 \mathrm{~h}$ in the dark. The MTT solution was then removed, and $100 \mu \mathrm{L}$ of isopropanol (Sigma-Aldrich, St. Louis, MO, USA) was added to each well. The plates were then shaken on a shaker for $20 \mathrm{~min}$ in the dark. Subsequently, the optical density was measured using an ELISA reader (Epoch, BioTek, Winooski, VT, USA) at $570 \mathrm{~nm}$. Cell viability was calculated using the following equation: Cell viability $(\%)=($ Optical density of treated cell $/$ Optical density of negative control $) \times 100$. Cell viability in the negative control group was considered to be $100 \%$, and the percentage values for the experimental groups were calculated. The MTT assay was repeated in five separate experiments.

Additionally, the morphology of the L929 cells on the 96-well plate after exposure to experimental and control solutions for $24 \mathrm{~h}$ was observed visually using an EVOS FL microscope (EVOS FL, Advanced Microscopy Group USA Ltd., Mill Creek, WA, USA) at $20 \times$ magnification $(n=2)$.

\subsection{Preparation of Microbial for Antimicrobial Test}

To determine the antimicrobial potential of various concentrations of Reynoutria elliptica extract, Streptococcus mutans (ATCC 25175) and Candida albicans (ATCC 10231) were selected as test microorganisms. Streptococcus mutans was cultured in brain heart infusion (BHI, Becton Dickinson and Co., MD, USA) and C. albicans in yeast mold (YM, Becton Dickinson and Co., Franklin Lakes, NJ, USA), and then both were incubated at $37^{\circ} \mathrm{C}$ for $24 \mathrm{~h}$ under aerobic conditions.

\subsection{Antimicrobial Tests}

To prepare the experimental solution, Reynoutria elliptica extract powder was dissolved in dimethyl sulfoxide (DMSO, Sigma-Aldrich, St. Louis, MO, USA) to achieve concentrations of $50 \mu \mathrm{g} / \mathrm{mL}$, $100 \mu \mathrm{g} / \mathrm{mL}, 150 \mu \mathrm{g} / \mathrm{mL}$ and $200 \mu \mathrm{g} / \mathrm{mL}$. In addition, DMSO without Reynoutria elliptica extract was also prepared to establish a negative control for the antimicrobial tests.

To study growth inhibition in a culture medium, microbial suspensions were diluted with each culture solution to establish an OD value within the range of $0.4-0.6$ at $600 \mathrm{~nm}$. Subsequently, the experimental solution and microbial suspension was mixed in a 9:1 ratio and incubated at $37^{\circ} \mathrm{C}$ for $6 \mathrm{~h}, 12 \mathrm{~h}$, and $24 \mathrm{~h}$. A reaction mixture containing no Reynoutria elliptica extract was also cultured 
under the same conditions to prepare the control group. Then, the growth inhibitory effect of the experimental groups was estimated by using an ELISA reader to measure OD values (600 $\mathrm{nm}$ ) after the three different time intervals.

To examine the microbial colony-forming unit (CFU), each experimental solution was added into microbial suspensions $\left(1 \times 10^{5}\right.$ cells $\left./ \mathrm{mL}\right)$ at a $1: 1$ ratio and incubated at $37^{\circ} \mathrm{C}$ for $24 \mathrm{~h}$. A reaction mixture without Reynoutria elliptica extract was also cultured under the same conditions to establish the control group. One hundred microliter of this mixture was then spread onto BHI and YM agar plates and incubated at $37^{\circ} \mathrm{C}$ for $24 \mathrm{~h}$, respectively. After incubation, the total viable cells were counted according to the number of CFUs.

To perform the agar disk diffusion test, $100 \mu \mathrm{L}$ of microbial suspension $\left(1 \times 10^{4}\right.$ cells $\left./ \mathrm{mL}\right)$ was spread uniformly onto BHI and YM agar plates. Twenty microliters of the experimental solution were impregnated into a sterile paper disk with a diameter of $10 \mathrm{~mm}$ and thickness of $1 \mathrm{~mm}$, and this was then placed on the surface of the agar plates, which had been inoculated with $S$. mutans and C. albicans suspension, respectively. Blank disks impregnated with DMSO were used as a negative control and also placed with the experimental group. The plates were then incubated for $24 \mathrm{~h}$ at $37^{\circ} \mathrm{C}$, and the size of the inhibition zone around each sample was measured with Vernier calipers (Mitutoyo, Kawasaki, Japan), with an accuracy of $\pm 0.01 \mathrm{~mm}$.

To examine further the effect of the Reynoutria elliptica extract on microbial morphology, $0.5 \mathrm{~mL}$ of each experimental solution was added into microbial suspensions $\left(1 \times 10^{5}\right.$ cells $\left./ \mathrm{mL}\right)$ at 1:1 ratios. Subsequently, the $1 \mathrm{~mL}$ of the microbial suspension and experimental solution was added to a 24-well plate (Thermo Fisher Scientific Inc., Waltham, MA, USA) and incubated at $37^{\circ} \mathrm{C}$ for $24 \mathrm{~h}$. For microscopic examination, the $S$. mutans and C. albicans were fixed with $2 \%$ glutaraldehyde/paraformaldehyde in $0.1 \mathrm{M}$ PBS for $30 \mathrm{~min}$ at room temperature $\left(25 \pm 1^{\circ} \mathrm{C}\right)$. The fixed $S$. mutans and $\mathrm{C}$. albicans were then post-fixed with $1 \% \mathrm{OsO}_{4}$ dissolved in $0.1 \mathrm{M}$ PBS for $2 \mathrm{~h}$, dehydrated with an ascending gradual series of ethanol, treated with isoamyl acetate, and then subjected to critical point drying (LEICA EM CPD300; Leica, Wien, Austria). The S. mutans and C. albicans was then sputter-coated with Pt and observed using a scanning electron microscopy (FE-SEM; Merin, Carl Zeiss, Oberkochen, Germany) with an accelerating voltage of $2.0 \mathrm{kV}$.

All antimicrobial experiments except for the SEM observations were independently performed with five repetitive tests for each microbial strain, and data were recorded as means and standard deviations.

\subsection{Extract Analysis}

To analyze the extracts from the experimental solution, Reynoutria elliptica extract powder was dissolved in distilled water to achieve the concentrations $50 \mu \mathrm{g} / \mathrm{mL}, 100 \mu \mathrm{g} / \mathrm{mL}, 150 \mu \mathrm{g} / \mathrm{mL}$, and $200 \mu \mathrm{g} / \mathrm{mL}$, and the solutions were then held at $37 \pm 1^{\circ} \mathrm{C}$ in a water bath for $24 \mathrm{~h}$.

To quantify the polyphenol content, $50 \mu \mathrm{L}$ of the extract experimental solution and $50 \mu \mathrm{L}$ of Folin Denis reagent were added to $650 \mu \mathrm{L}$ of distilled water and allowed to react at room temperature $\left(25 \pm 1^{\circ} \mathrm{C}\right)$ for $3 \mathrm{~min}$. One hundred microliter of $10 \% \mathrm{Na}_{2} \mathrm{CO}_{3}$ solution and $150 \mu \mathrm{L}$ of distilled water were added to the reacted solution to establish a final volume of $1 \mathrm{~mL}$. These pretreated extracts were stored at $37 \pm 1^{\circ} \mathrm{C}$ for $60 \mathrm{~min}$ in a dark environment. The absorbance at $725 \mathrm{~nm}$ was subsequently determined using a UV/VIS spectrophotometer (X-ma 1200 Spectrophotometer, Human Corp., Seoul, Korea). Gallic acid (Sigma-Aldrich, St Louis, MO, USA) was used as a standard material to construct a calibration curve $(20,40,60,80$, and $100 \mu \mathrm{g} / \mathrm{mL})$. Using the calibration curve created with standard material, the total polyphenol content was calculated in $\mu \mathrm{g}$ of gallic acid equivalents.

To quantify the flavonoid content, $100 \mu \mathrm{L}$ of the experimental solution and $1 \mathrm{~mL}$ of diethylene glycol was added to $100 \mu \mathrm{L}$ of $1 \mathrm{~N}$ sodium hydroxide and allowed to react at a temperature of $37 \pm 1^{\circ} \mathrm{C}$ for $60 \mathrm{~min}$. The absorbance at $420 \mathrm{~nm}$ was subsequently determined with a UV/VIS spectrophotometer. Naringin (Sigma-Aldrich, St Louis, MO, USA) was used as a standard material to construct the calibration curve $(20,40,60,80$, and $100 \mu \mathrm{g} / \mathrm{mL})$. Using the calibration curve created with standard material, the total flavonoid content was calculated in $\mu \mathrm{g}$ of naringin equivalents. 


\subsection{Statistical Analysis}

All test results from the control and experimental groups were analyzed with one-way ANOVA (PASW 18.0, IBM Co., Armonk, NY, USA) to confirm the interactions with various concentrations of Reynoutria elliptica extract. To determine significant differences within these concentrations, post-hoc analyses were carried out with Tukey's multiple comparison test at a significance level of 0.05.

\section{Results}

\subsection{Cell Viability and Morphology}

One-way ANOVA revealed significant differences in cell viability among the different concentration groups $(p<0.05)$ (Figure 1A). The results exhibited decreasing levels of cell viability with increasing concentrations of Reynoutria elliptica extract, and the $200 \mu \mathrm{g} / \mathrm{mL}$ group presented the lowest cell viability value $(p<0.05)$. The $50 \mu \mathrm{g} / \mathrm{mL}$ group had a cell viability of $91.5 \pm 9.4 \%$, which was significantly higher than that of the other groups $(p<0.05)$. The groups with $100 \mu \mathrm{g} / \mathrm{mL}$ and $150 \mu \mathrm{g} / \mathrm{mL}$ concentrations exhibited no significant difference $(p>0.05)$ in cell viability. Additionally, all experimental groups (except for the $200 \mu \mathrm{g} / \mathrm{mL}$ group) showed cell viability greater than $70 \%$, and these values are considered to indicate non-cytotoxic behavior (based on ISO biocompatibility criteria).

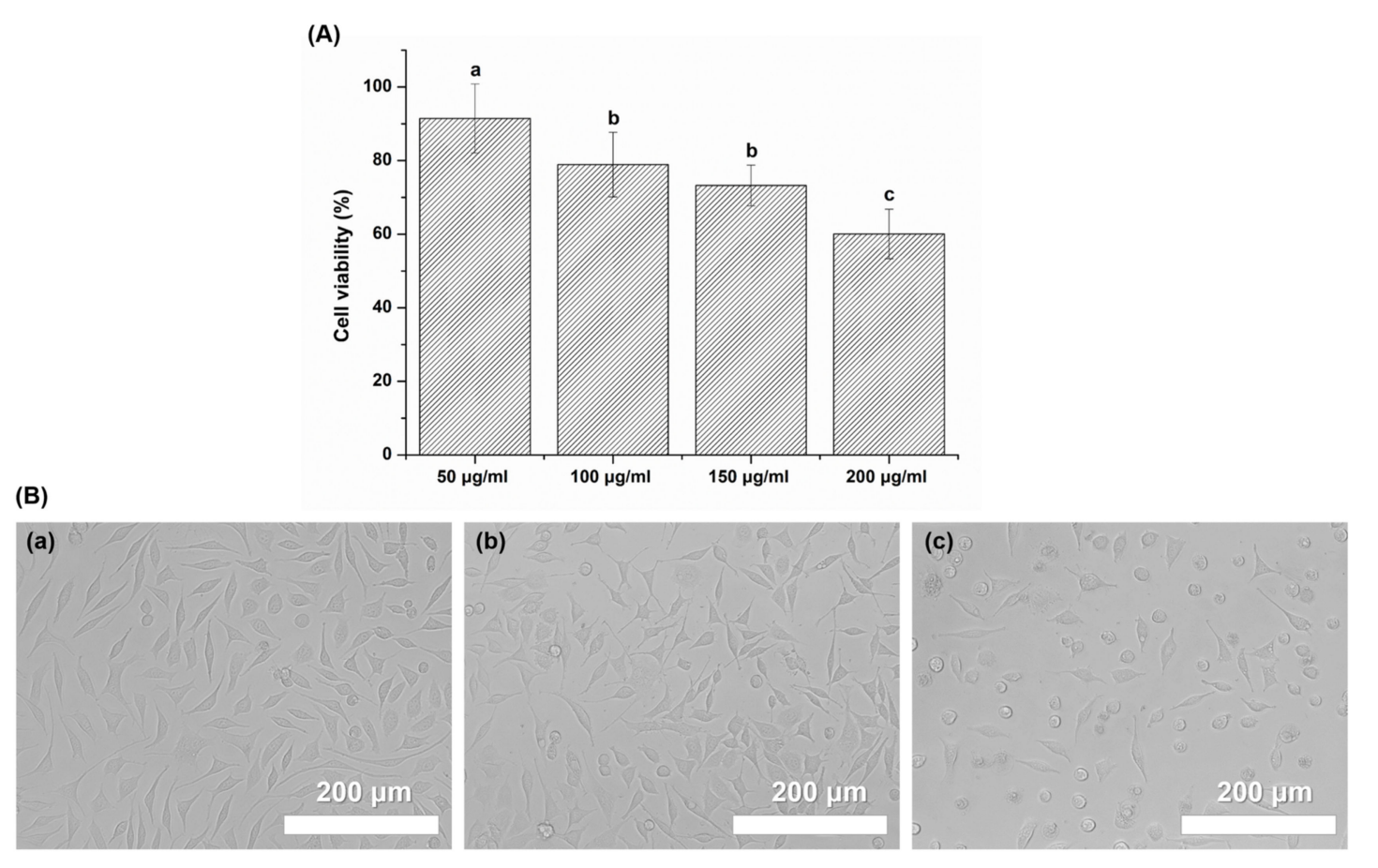

Figure 1. (A) Cell viability of each experimental groups $(50 \mu \mathrm{g} / \mathrm{mL}, 100 \mu \mathrm{g} / \mathrm{mL}, 150 \mu \mathrm{g} / \mathrm{mL}$ and $200 \mu \mathrm{g} / \mathrm{mL}$ ). The same lowercase letter indicates no significant differences in cell viability between the group ( $p$ > 0.05). (B (a)) L929 cells exposed to negative control for 24 h. (B (b)) L929 cells exposed to Reynoutria elliptica extract at a concentration of $50 \mu \mathrm{g} / \mathrm{mL}$ for $24 \mathrm{~h}$. (B (c)) L929 cells exposed to Reynoutria elliptica extract at a concentration of $200 \mu \mathrm{g} / \mathrm{mL}$ for $24 \mathrm{~h}$.

With a decreasing concentration of Reynoutria elliptica extract, the cells demonstrated the typical stellate appearance of the L929 cells (Figure 1B). The cells in the $50 \mu \mathrm{g} / \mathrm{mL}$ group showed a morphological appearance similar to that of the control group, but revealed a reduced tendency, relative to the control group, to attach to the surface of the culture plate. When the concentration of the Reynoutria elliptica extract was increased, the cells showed a toxic response; the cells in the $200 \mu \mathrm{g} / \mathrm{mL}$ group became rounded and lost the structural organization seen in the control group. 


\subsection{Optical Density}

Figure 2 shows that the Reynoutria elliptica extract significantly affected the OD values for both S. mutans and C. albicans, as compared with the control group $(p<0.05)$. The control group showed higher OD values at various cultivation times than did the experimental groups $(p<0.05)$, with the only exception being the S. mutans sample cultivated for $6 \mathrm{~h}$. The OD values for the $S$. mutans and C. albicans experimental groups at various cultivation times were not significantly different, despite the increase in the Reynoutria elliptica extract concentration $(p>0.05)$.

(A)

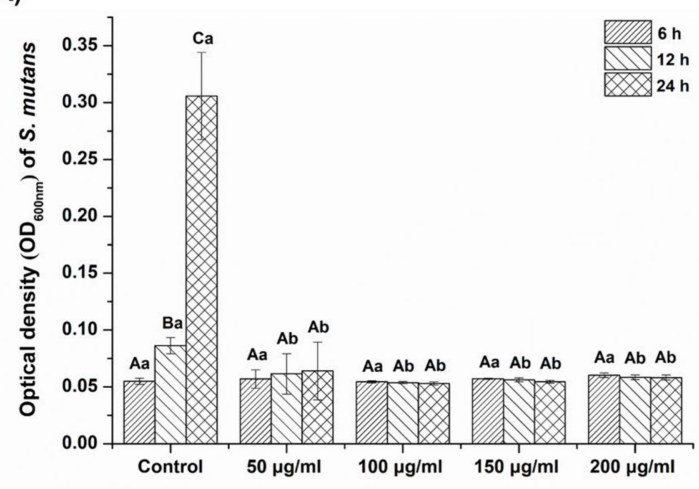

(B)

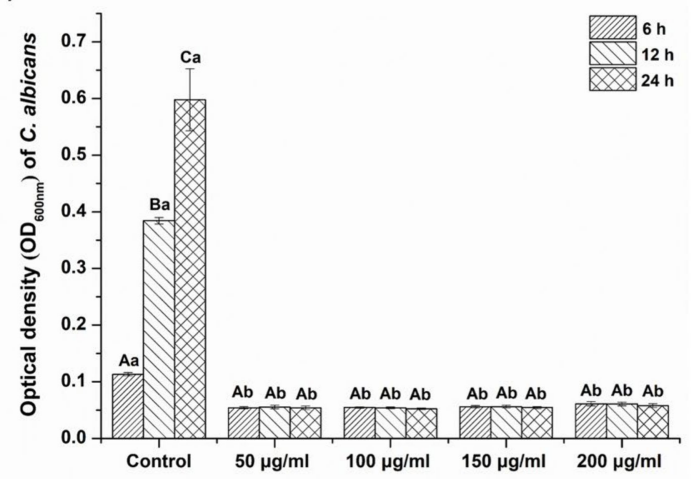

Figure 2. Optical density $\left(\mathrm{OD}_{600 \mathrm{~nm}}\right)$ of each experimental group $(50 \mu \mathrm{g} / \mathrm{mL}, 100 \mu \mathrm{g} / \mathrm{mL}, 150 \mu \mathrm{g} / \mathrm{mL}$ and $200 \mu \mathrm{g} / \mathrm{mL}$ ) with (A) Streptococcus mutans and (B) Candida albicans at three different times, compared with a control group. The same lowercase letter $(\mathbf{a}-\mathbf{b})$ indicates no significant differences in optical density between the group at each time point $(p>0.05)$. The same uppercase letter $(\mathbf{A}-\mathbf{C})$ indicates no significant differences in optical density value among three different times for each group $(p>0.05)$.

As shown in Figure 2, there were no differences in OD values for any experimental group containing Reynoutria elliptica extract. Conversely, the OD values for the control group without Reynoutria elliptica increased nearly 6-fold between the 6- and 24-h times for both S. mutans and C. albicans $(p<0.05)$. These results demonstrate that the Reynoutria elliptica extract significantly inhibited the growth of S. mutans and C. albicans.

\section{3. $C F U$}

One-way ANOVA revealed that the CFU of the experimental groups was significantly lower than was that of the control group with both S. mutans and C. albicans $(p<0.05)$ (Figure 3). However, the CFUs for $S$. mutans did not differ significantly among experimental groups, despite the increase in the Reynoutria elliptica extract concentration $(p>0.05)$. In the case of $C$. albicans, the results showed a decreasing trend for CFU with an increasing concentration of Reynoutria elliptica extract. The CFU value for the $150 \mu \mathrm{g} / \mathrm{mL}$ sample $(103.25 \pm 8.42)$ was not significantly different from that of the $200 \mu \mathrm{g} / \mathrm{mL}$ sample $(97.25 \pm 12.45)(p>0.05)$. Additionally, the CFU for the $50 \mu \mathrm{g} / \mathrm{mL}$ sample $(180.00 \pm 15.60)$ was not significantly different from that of the $100 \mu \mathrm{g} / \mathrm{mL}$ sample $(170.25 \pm 10.44)(p>0.05)$. These results demonstrated that Reynoutria elliptica extract significantly inhibited colony formation with S. mutans and C. albicans. 
(A)

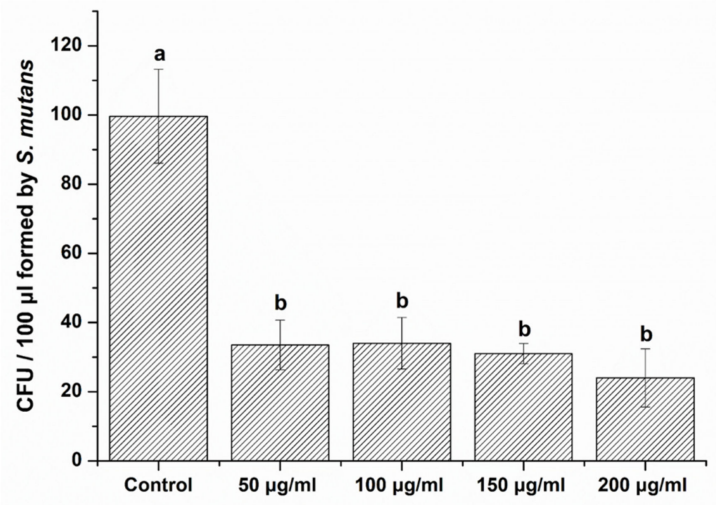

(B)

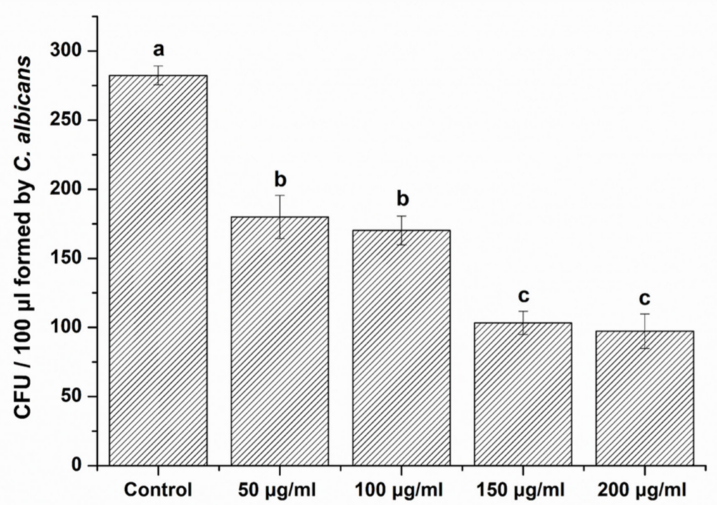

Figure 3. Colony-forming units (CFU) number for each experimental group $(50 \mu \mathrm{g} / \mathrm{mL}, 100 \mu \mathrm{g} / \mathrm{mL}$, $150 \mu \mathrm{g} / \mathrm{mL}$ and $200 \mu \mathrm{g} / \mathrm{mL}$ ) with (A) Streptococcus mutans and (B) Candida albicans, compared with a control group. The same lowercase letter $(\mathbf{a}-\mathbf{c})$ indicates no significant difference in CFU values between the groups of a given microbial $(p>0.05)$.

\subsection{Growth Inhibition on Agar Plates}

The antimicrobial activities for different concentrations of Reynoutria elliptica extract were screened with the agar disk diffusion method, which is a technique for confirming antimicrobial potency according to the size of a transparent circle formed by restraining the growth of microbials around experimental materials on agar plates. The inhibition zones for different experimental groups did not differ significantly, despite increases in the Reynoutria elliptica extract concentrations on the S. mutans agar plate $(p>0.05)$ (Figure $4 \mathrm{~A})$. In contrast, the inhibition zone was significantly enlarged with higher concentrations of the Reynoutria elliptica extract on the C. albicans agar plate $(p<0.05)$.

(A)

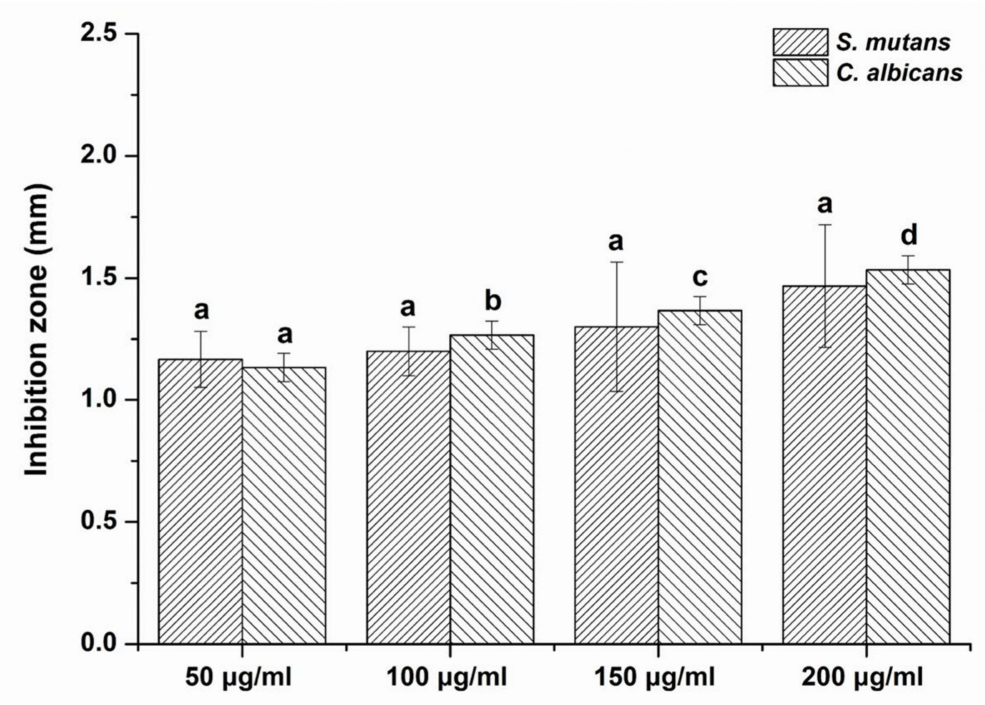

(B)

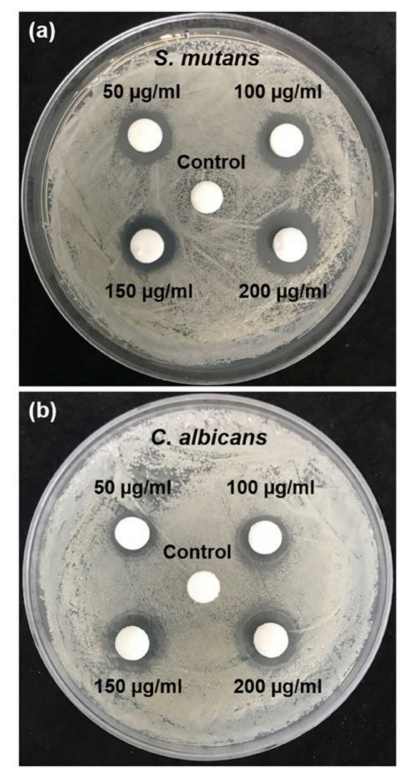

Figure 4. (A) Inhibition zone size for each experimental group $(50 \mu \mathrm{g} / \mathrm{mL}, 100 \mu \mathrm{g} / \mathrm{mL}, 150 \mu \mathrm{g} / \mathrm{mL}$ and $200 \mu \mathrm{g} / \mathrm{mL}$ ) on Streptococcus mutans and Candida albicans agar plates. The same lowercase letter (a-d) indicates that there was no significant difference in inhibition zone sizes for the experimental groups of the two microbial $(p>0.05)$. (B) Images of the inhibition zones for various concentrations of Reynoutria elliptica extract with (a) Streptococcus mutans and (b) Candida albicans agar plates. 
Figure 4B shows microbial static rings produced around the experimental disks, which indicated that Reynoutria elliptica extract had an antimicrobial effect on both S. mutans and C. albicans. DMSO-treated disks used as negative controls (spot in the middle of the plate) showed no zone of inhibition with either S. mutans or C. albicans.

\subsection{Morphological Observations Using SEM}

SEM was used to visualize structural differences for the two types of microbials, relative to those of the control groups (Figure 5). The microbial morphologies of both control groups showed intact and smooth surfaces without cell debris or lysis (Figure 5a,b,g and h). The control group for S. mutans exhibited relatively aggregated long chains and differed from the experimental groups in this respect. Additionally, S. mutans was formed by the linkage of diplococci, which were composed of a few cocci connected by a wall band. However, for the experimental groups that contained Reynoutria elliptica extract, the microbial morphology and density were significantly changed and showed fewer intact cells than did the control group. Streptococcus mutans cells treated with Reynoutria elliptica extract showed defective morphologies and intracellular contents with rough surfaces and without wall bands. As the concentration of Reynoutria elliptica extract was increased, the S. mutans cells had small debris and demonstrated loss of their native shape. The control group for C. albicans exhibited a larger number of yeast cells than did the $200 \mu \mathrm{g} / \mathrm{mL}$ group. Candida albicans cells treated with Reynoutria elliptica extract showed visible swelling and obscured surfaces. However, there were no morphological differences for the C. albicans cells treated with various concentrations of Reynoutria elliptica extract (relative to those in the control group). These results demonstrate that Reynoutria elliptica extract significantly inhibited the formation of $S$. mutans and C. albicans.

S. mutans

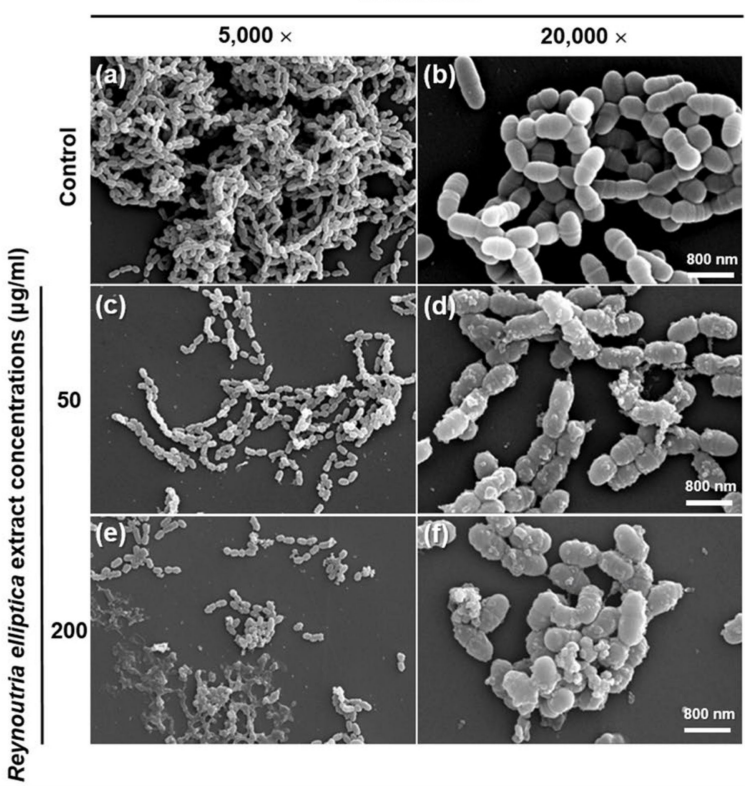

C. albicans

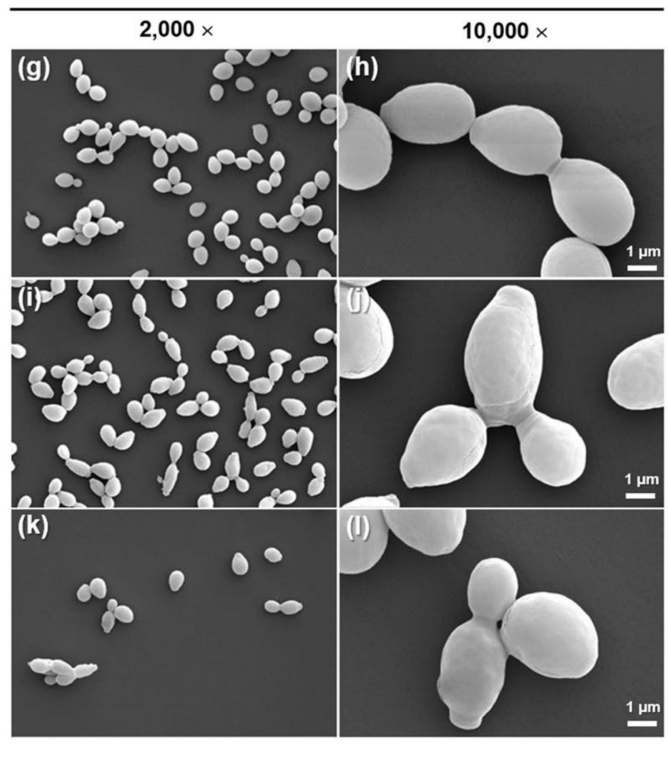

Figure 5. Scanning electron micrographs of Streptococcus mutans and Candida albicans treated with various concentrations of Reynoutria elliptica extract for $24 \mathrm{~h}$. For Streptococcus mutans with Reynoutria elliptica extract, images (a) and (b) show to the control group that was not exposed to Reynoutria elliptica extract. Images (c) and (d) show Streptococcus mutans exposed to $50 \mu \mathrm{g} / \mathrm{mL}$ of Reynoutria elliptica extract. Images (e) and (f) show Streptococcus mutans exposed to $200 \mu \mathrm{g} / \mathrm{mL}$ of Reynoutria elliptica extract. For Candida albicans with Reynoutria elliptica extract, images (g) and (h) show to the control group that was not exposed to Reynoutria elliptica extract. Images (i) and (j) show Candida albicans exposed to $50 \mu \mathrm{g} / \mathrm{mL}$ of Reynoutria elliptica extract. Images (k) and (1) show Candida albicans exposed to $200 \mu \mathrm{g} / \mathrm{mL}$ of Reynoutria elliptica extract. Magnification factors are indicated at the top of each column. 


\subsection{Analysis of Polyphenol and Flavonoid Contents}

Increasing the Reynoutria elliptica extract concentration significantly increased the content of polyphenol and flavonoid $(p<0.05)$ (Table 1$)$. The contents of polyphenol and flavonoid for the $200 \mu \mathrm{g} / \mathrm{mL}$ group were significantly higher than were those of the other groups $(p<0.05)$. The content of flavonoid for the $100 \mu \mathrm{g} / \mathrm{mL}$ group was not significantly different from that of the $150 \mu \mathrm{g} / \mathrm{mL}$ group $(p>0.05)$.

Table 1. Contents of detected polyphenol and flavonoid in experimental groups. Each value is the average \pm standard deviation for 6 measurements.

\begin{tabular}{ccc}
\hline Experimental Group & Polyphenol Content $(\mu \mathrm{g} / \mathrm{mL})$ & Flavonoid Content $(\mu \mathrm{g} / \mathrm{mL})$ \\
\hline $50 \mu \mathrm{g} / \mathrm{mL}$ & $41.2 \pm 3.9^{\mathrm{a}}$ & $21.3 \pm 1.5^{\mathrm{a}}$ \\
$100 \mu \mathrm{g} / \mathrm{mL}$ & $56.7 \pm 2.9^{\mathrm{b}}$ & $24.1 \pm 0.9^{\mathrm{b}}$ \\
$150 \mu \mathrm{g} / \mathrm{mL}$ & $65.7 \pm 1.7^{\mathrm{c}}$ & $25.4 \pm 0.9^{\mathrm{b}}$ \\
$200 \mu \mathrm{g} / \mathrm{mL}$ & $94.0 \pm 6.4^{\mathrm{d}}$ & $27.9^{\mathrm{c}} \mathrm{m}^{\mathrm{c}}$ \\
\hline
\end{tabular}

The same lowercase letters (a-d) indicate no differences in polyphenol or flavonoid content among experimental groups within each row $(p>0.05)$.

\section{Discussion}

An ideal antibacterial and antifungal agent for the oral environment must exhibit excellent and selective antibacterial and antifungal action against dental caries, periodontitis, or microorganisms, causing bad breath. In recent years, studies have been carried out on various plant-derived natural extracts that are safe for oral mucosa and can replace antibiotics while continuously acting without side effects [44-46]. The Reynoutria elliptica extract used in this study, a natural material derived from plants, contains many substances with significant physiological activity, such as phenol compounds, stilbene derivatives, anthraquinone derivatives, and flavonoid compounds [39,47]. Physiological effects of Reynoutria elliptica extract, such as anti-inflammatory, antioxidant, anti-hepatitis virus, and antibacterial activities, have been reported. However, studies on antimicrobial efficacy against oral pathogens such as S. mutans and C. albicans have not been clearly identified.

To the best of our knowledge, our study constitutes the first report of the biocompatibility and antimicrobial effects of Reynoutria elliptica extract derived from plants. Therefore, to provide necessary data for the development of oral products using Reynoutria elliptica extract to inhibit oral disease, we studied the biocompatibility and antimicrobial properties of Reynoutria elliptica extract using various experimental techniques and sought to assess its utility in the dental field.

To probe the effects of various concentrations of Reynoutria elliptica extract on cell viability rates, L929 cells were treated with four concentrations of Reynoutria elliptica extract, and biocompatibility was evaluated using MTT quantitative analysis according to the method of international standards [48]. As shown in Figure 1, it was observed that the Reynoutria elliptica extract produced very weak cytotoxicity at the $200 \mu \mathrm{g} / \mathrm{mL}$ concentration. Additionally, extracts with concentrations lower than $200 \mu \mathrm{g} / \mathrm{mL}$ showed cell viabilities greater than $70 \%$, which meets the criteria for non-cytotoxicity in international standard specifications, and morphological observations also showed no other variations in cells in the experimental groups (as compared to normal L929 cells). Even when treated with Reynoutria elliptica extract at concentrations up to $150 \mu \mathrm{g} / \mathrm{mL}$, cytotoxicity was not observed, and concentrations up to $150 \mu \mathrm{g} / \mathrm{mL}$ are considered to exhibit biocompatibility.

To investigate the effect of Reynoutria elliptica extract on the growth of pathogenic microorganisms in the oral cavity, S. mutans, bacteria that causes dental caries, and C. albicans, a fungus that causes oral candidiasis, were cultured with experimental groups for various time intervals and then absorbance values were determined. As shown in Figure 2, all microbial samples showed the inhibition of microbial growth without significant dependence on the concentration of Reynoutria elliptica extract. Conversely, the results of CFU studies showed that the antimicrobial effects seen with various Reynoutria elliptica extract concentrations differed for the two microorganisms. Unlike the studies with S. mutans, 
those with C. albicans showed significantly higher antifungal activities with higher concentrations of Reynoutria elliptica extract. Similar trends were seen in the agar disk diffusion tests conducted in this study. Studies using various concentrations of Reynoutria elliptica extract impregnated into paper disks exhibited the formation of transparent circles around the disks, indicating inhibition of the growth of $S$. mutans and $C$. albicans. In addition, the sizes of the transparent circles were found to depend on the concentrations of Reynoutria elliptica extract in the disks. As with the CFU studies, higher concentrations in the experimental group with $C$. albicans led to significantly higher antifungal activity. These results suggest that, when using Reynoutria elliptica extract for its antimicrobial effects in the oral cavity, the following factors should be considered. If treatment is intended to prevent oral candidiasis, the inhibition of micro fungal activity can be controlled successfully with variations in the concentration of Reynoutria elliptica extract. In addition, if it is intended to prevent tooth caries, it may be assumed that any concentration of Reynoutria elliptica extract used in this study will show similar antibacterial activity. SEM imaging is a useful method for qualitative evaluation of microbial forms, and we have used it in this study to observe how Reynoutria elliptica extract affects the morphology of microorganisms. As can be seen from the SEM results, the Reynoutria elliptica extract caused obscured cell bands on $S$. mutans, induced debris on the surface, and interfered with growth, thereby reducing the density of the bacteria. The use of Reynoutria elliptica extract with C. albicans causes the cells to swell and induces obscured surfaces and interferes with growth, thereby lowering the density of fungi. These results were similar to the results seen for the treatment of S. mutans with Curcuma xanthorrhiza extract [49], and the effect of Reynoutria elliptica extract on the morphological characteristics of pathogenic microorganisms was confirmed in the present study.

The phenolic compounds are secondary metabolites contained in the plant system, and they exhibit physiological activity functions such as antioxidant and antibacterial activities [50,51]. The results of extraction analyses showed that high polyphenol and flavonoid contents were observed as the concentration of the Reynoutria elliptica extract was increased. Previous studies have shown an association between phenolic compounds and antimicrobial activity, and it has been reported that there is an inhibitory effect on microorganism growth that is proportional to the content of phenolic compounds contained in plant extracts [52]. Therefore, it is presumed that the polyphenol and flavonoid components contained in the Reynoutria elliptica extract used herein have an inhibitory effect on the S. mutans and C. albicans activities and on their abilities to serve as pathogens in the oral cavity.

When the results of the above studies are combined, our null hypothesis is partially rejected. This study compared the biocompatibility and antimicrobial effects of Reynoutria elliptica extract with varying concentrations. In future studies, it will be necessary to expand this study through prolonged long-term comparative studies involving Listerine $($ (Johnson \& Johnson, New Brunswick, NJ, USA), an oral product based on natural extracts. Listerine ${ }^{\circledR}$ is a mouthwash containing essential oils and active ingredients such as $0.092 \%$ eucalyptol, $0.064 \%$ thymol, $0.060 \%$ methyl salicylate, and $0.042 \%$ menthol, and its antibacterial effects have been found in a number of studies [53-55]. However, various side effects have been reported, including the poor taste, reversible palatal erythema, burning sensation, and instability of restorative materials resulting from use [56-58]. Thus, it is thought that Reynoutria elliptica extract, which has low cytotoxicity and can be applied in various concentrations, can be developed as an effective antimicrobial agent against oral pathogens while proving safe for the human body. In this study, since $150 \mu \mathrm{g} / \mathrm{mL}$ concentrations showed no toxicity to L929 cells and showed no significant difference from $200 \mu \mathrm{g} / \mathrm{mL}$ concentrations, it is assumed that the use of oral products using these concentrations would be appropriate for patients suffering from oral diseases such as dental caries or oral candidiasis.

\section{Conclusions}

The following results were obtained by probing cytotoxicity and antimicrobial activity with various Reynoutria elliptica extract concentrations. 
In cell viability tests, the Reynoutria elliptica extract used in this study exhibited a slight cytotoxic effect at a $200 \mu \mathrm{g} / \mathrm{mL}$ concentration, with a viability rate of approximately $60 \%$ for L929 cells. However, at concentrations of $150 \mu \mathrm{g} / \mathrm{mL}$ or less, cell viability was $70 \%$ or more, this value meets the international standard for biocompatibility. In the antimicrobial tests, antibacterial and antifungal effects exhibited significant differences when compared to the negative control. In particular, S. mutans showed an antibacterial effect with no significant difference between experimental groups, regardless of the concentration of the Reynoutria elliptica extract. However, C. albicans showed an antifungal effect with significant differences depending on the concentration of the Reynoutria elliptica extract. In addition, SEM images showed that Reynoutria elliptica extract had a significant effect on the morphology and density of the $S$. mutans and C. albicans cells.

Overall, the results show that Reynoutria elliptica extract at a concentration of $150 \mu \mathrm{g} / \mathrm{mL}$ has excellent antimicrobial effects on S. mutans and C. albicans, without negatively affecting cell viability and morphology. Accordingly, the results of this research can be used when incorporating Reynoutria elliptica extract into oral products that are biologically friendly and capable of controlling oral diseases such as dental caries and oral candidiasis.

Author Contributions: S.-Y.Y. contributed to design, data acquisition, and analysis, and drafted the manuscript; M.-K.K. contributed to design, data interpretation, and critically revised the manuscript. Both authors have read and agreed to the published version of the manuscript.

Funding: This study was supported by the National Research Foundation of Korea (NRF) grant funded by the Korea government (MIST) (No.2017R1C1B5076310).

Conflicts of Interest: The authors declare no conflict of interest.

\section{References}

1. Metwalli, K.H.; Khan, S.A.; Krom, B.P.; Jabra-Rizk, M.A. Streptococcus mutans, Candida albicans, and the human mouth: A sticky situation. PLoS Pathog. 2013, 9, e1003616. [CrossRef] [PubMed]

2. Saxton, C.A. Scanning electron microscope study of the formation of dental plaque. Caries Res. 1973, 7, 102-119. [CrossRef] [PubMed]

3. Sakamoto, M.; Huang, Y.; Ohnishi, M.; Umeda, M.; Ishikawa, I.; Benno, Y. Changes in oral microbial profiles after periodontal treatment as determined by molecular analysis of 16S rRNA genes. J. Med. Microbiol. 2004, 53, 563-571. [CrossRef] [PubMed]

4. Capasso, C.; Supuran, C.T. An Overview of the Carbonic Anhydrases from Two Pathogens of the Oral Cavity: Streptococcus mutans and Porphyromonas gingivalis. Curr. Tops. Med. Chem. 2016, 16, 2359-2368. [CrossRef]

5. Almståhl, A.; Wikström, M. Oral microflora in subjects with reduced salivary secretion. J. Dent. Res. 1999, 78, 1410-1416. [CrossRef]

6. Theilade, E. The non-specific theory in microbial etiology of inflammatory periodontal diseases. J. Clin. Periodontol. 1986, 13, 905-911. [CrossRef]

7. Baelum, V.; Fejerskov, O. Tooth loss as related to dental caries and periodontal breakdown in adult Tanzanians. Community Dent. Oral Epidemiol. 1986, 14, 353-357. [CrossRef]

8. Ismail, A.I.; Burt, B.A.; Brunelle, J.A. Prevalence of total tooth loss, dental caries, and periodontal disease in Mexican-American adults: Results from the southwestern HHANES. J. Dent. Res. 1987, 66, 1183-1188. [CrossRef]

9. Da'ameh, D. Reasons for permanent tooth extraction in the North of Afghanistan. J. Dent. 2006, 34, 48-51. [CrossRef]

10. Da Silva, B.R.; de Freitas, V.A.; Nascimento-Neto, L.G.; Carneiro, V.A.; Arruda, F.V.; de Aguiar, A.S.; Cavada, B.S.; Teixeira, E.H. Antimicrobial peptide control of pathogenic microorganisms of the oral cavity: A review of the literature. Peptides 2012, 36, 315-321. [CrossRef]

11. Hattori, M.; Kusumoto, I.T.; Namba, T.; Ishigami, T.; Hara, Y. Effect of tea polyphenols on glucan synthesis by glucosyltransferase from Streptococcus mutans. Chem. Pharm. Bull. 1990, 38, 717-720. [CrossRef] [PubMed]

12. Hamada, S.; Torii, M. Interaction of glucosyltransferase from Streptococcus mutans with various glucans. J. Gen. Microbiol. 1980, 116, 51-59. [CrossRef] 
13. Takahashi-Abbe, S.; Abbe, K.; Takahashi, N.; Tamazawa, Y.; Yamada, T. Inhibitory effect of sorbitol on sugar metabolism of Streptococcus mutans in vitro and on acid production in dental plaque in vivo. Oral Microbiol. Immunol. 2001, 16, 94-99. [CrossRef] [PubMed]

14. Ccahuana-Vásquez, R.A.; Cury, J.A.S. mutans biofilm model to evaluate antimicrobial substances and enamel demineralization. Braz. Oral Res. 2010, 24, 135-141. [CrossRef]

15. Köhler, B.; Andréen, I.; Jonsson, B. The effect of caries-preventive measures in mothers on dental caries and the oral presence of the bacteria Streptococcus mutans and lactobacilli in their children. Arch. Oral Biol. 1984, 29, 879-883. [CrossRef]

16. Loesche, W.J. Role of Streptococcus mutans in human dental decay. Microbiol. Rev. 1986, 50, 353-380. [CrossRef] [PubMed]

17. Dongari-Bagtzoglou, A.; Kashleva, H.; Dwivedi, P.; Diaz, P.; Vasilakos, J. Characterization of mucosal Candida albicans biofilms. PLoS ONE 2009, 4, e7967. [CrossRef] [PubMed]

18. Cannon, R.; Chaffin, W. Oral colonization by Candida albicans. Crit. Rev. Oral Biol. Med. 1999, 10, $359-383$. [CrossRef]

19. Salerno, C.; Pascale, M.; Contaldo, M.; Esposito, V.; Busciolano, M.; Milillo, L.; Guida, A.; Petruzzi, M.; Serpico, R. Candida-associated denture stomatitis. Med. Oral Patol. Oral Cir. Bucal. 2011, 16, e139-e143. [CrossRef]

20. Budtz-Jorgensen, E. The significance of Candida albicans in denture stomatitis. Eur. J. Oral Sci. 1974, 82, 151-190. [CrossRef]

21. Iacopino, A.M.; Wathen, W.F. Oral candidal infection and denture stomatitis: A comprehensive review. J. Am. Dent. Assoc. 1992, 123, 46-51. [CrossRef] [PubMed]

22. Goldblum, D.; Frueh, B.E.; Sarra, G.-M.; Katsoulis, K.; Zimmerli, S. Topical caspofungin for treatment of keratitis caused by Candida albicans in a rabbit model. Antimicrob. Agents Chemother. 2005, 49, 1359-1363. [CrossRef] [PubMed]

23. Bunetel, L.; Bonnaure-Mallet, M. Oral pathoses caused by Candida albicans during chemotherapy: Update on development mechanisms. Oral Surg. Oral Med. Oral Pathol. Oral Radiol. Endodontology. 1996, 82, 161-165. [CrossRef]

24. Karadağlıŏlu, Ö.İ.; Ulusoy, N.; Başer, K.H.C.; Hanoğlu, A.; Şık, İ. Antibacterial activities of herbal toothpastes combined with essential oils against Streptococcus mutans. Pathogens 2019, 8, 20. [CrossRef]

25. Zaura-Arite, E.; Van Marle, J.; Ten Cate, J. Confocal microscopy study of undisturbed and chlorhexidine-treated dental biofilm. J. Dent. Res. 2001, 80, 1436-1440. [CrossRef]

26. Marsh, P. Controlling the oral biofilm with antimicrobials. J. Dent. 2010, 38, S11-S15. [CrossRef]

27. Waaler, S.M.; Rölla, G.; Skjörland, K.K.; Ögaard, B. Effects of oral rinsing with triclosan and sodium lauryl sulfate on dental plaque formation: A pilot study. Eur. J. Oral Sci. 1993, 101, 192-195. [CrossRef]

28. Hall, G.; Heimdahl, A.; Nord, C. Effects of prophylactic administration of cefaclor on transient bacteremia after dental extraction. Eur. J. Clin. Microbiol. Infect. Dis. 1996, 15, 646-649. [CrossRef]

29. Ready, D.; Roberts, A.; Pratten, J.; Spratt, D.; Wilson, M.; Mullany, P. Composition and antibiotic resistance profile of microcosm dental plaques before and after exposure to tetracycline. J. Antimicrob. Chemother. 2002, 49, 769-775. [CrossRef]

30. Walker, C.B. Selected antimicrobial agents: Mechanisms of action, side effects, and drug interactions. Periodontology 2000 1996, 10, 12-28. [CrossRef]

31. Poveda Roda, R.; Bagán, J.V.; Sanchis Bielsa, J.M.; Carbonell Pastor, E. Antibiotic use in dental practice: A review. Med. Oral Patol. Oral Y Cirugía Bucal Internet 2007, 12, 186-192.

32. Kathiravan, M.K.; Salake, A.B.; Chothe, A.S.; Dudhe, P.B.; Watode, R.P.; Mukta, M.S.; Gadhwe, S. The biology and chemistry of antifungal agents: A review. Bioorg. Med. Chem. 2012, 20, 5678-5698. [CrossRef]

33. Ellepola, A.N.; Samaranayake, L.P. The effect of limited exposure to antifungal agents on the germ tube formation of oral Candida albicans. J. Oral Pathol. Med. 1998, 27, 213-219. [CrossRef] [PubMed]

34. Ahmad, A.; Husain, A.; Mujeeb, M.; Khan, S.A.; Najmi, A.K.; Siddique, N.A.; Damanhouri, Z.A.; Anwar, F. A review on therapeutic potential of Nigella sativa: A miracle herb. Asian Pac. J. Trop. Biomed. 2013, 3, 337-352. [CrossRef]

35. Kazemi, M. Chemical composition and antimicrobial, antioxidant activities, and anti-inflammatory potential of Achillea millefolium L., Anethum graveolens L., and Carum copticum L. essential oils. J. Herb. Med. 2015, 5, 217-222. [CrossRef]

36. Varsha, S.; Agrawal, R.; Sonam, P. Phytochemical screening and determination of anti-bacterial and anti-oxidant potential of Glycyrrhiza glabra root extracts. J. Environ. Res. Devel. 2013, 7, 1552-1558. 
37. Rasheed, A.; Haider, M. Antibacterial activity of camellia sinensis extracts against dental caries. Arch. Pharm. Res. 1998, 21, 348-352. [CrossRef]

38. Tahir, A.; Moeen, R. Comparison of antibacterial activity of water and ethanol extracts of Camellia sinensis (L.) Kuntze against dental caries and detection of antibacterial components. J. Med. Plants Res. 2011, 5, 4504-4510.

39. Lee, C.-H.; Kim, S.-L.; Lee, K.-B.; Yoo, Y.-C.; Ryu, S.-Y.; Song, K.-S. Neuraminidase Inhibitors from Reynoutria elliptica. Arch. Pharm. Res. 2003, 26, 367-374. [CrossRef]

40. Lee, G.; Choi, T.W.; Kim, C.; Nam, D.; Lee, S.-G.; Jang, H.-J.; Lee, J.-H.; Um, J.-Y.; Jung, S.H.; Shim, B.S. Anti-inflammatory activities of Reynoutria elliptica through suppression of mitogen-activated protein kinases and nuclear factor- $\mathrm{kB}$ activation pathways. Immunopharmacol. Immunotoxicol. 2012, 34, 454-464. [CrossRef]

41. Jo, H.; Lee, H.J.; Kim, C.Y.; Son, J.-K.; Jung, S.H. 8-Hydroxycalamenene isolated from the rhizomes of Reynoutria elliptica exerts neuroprotective effects both in vitro and in vivo. Food Chem. Toxicol. 2013, 51, 231-241. [CrossRef] [PubMed]

42. Lee, I.-S.; Im, H.-G.; Lee, S.-O. Growth Inhibition of Helicobacter pylorio by Reynoutria elliptica Migo. Korean J. Food Sci. Technol. 2003, 35, 1182-1187.

43. Bae, K.-H.; Ji, J.-M.; Park, K.-L. The antibacterial component from Cinnamomi Cortex against a cariogenic bacterium Streptococcus mutans OMZ 176. Arch. Pharm. Res. 1992, 15, 239-241. [CrossRef]

44. Savoia, D. Plant-derived antimicrobial compounds: Alternatives to antibiotics. Future Microbiol. 2012, 7, 979-990. [CrossRef] [PubMed]

45. Karygianni, L.; Cecere, M.; Skaltsounis, A.L.; Argyropoulou, A.; Hellwig, E.; Aligiannis, N.; Wittmer, A.; Al-Ahmad, A. High-level antimicrobial efficacy of representative Mediterranean natural plant extracts against oral microorganisms. Biomed Res. Int. 2014, 1-8. [CrossRef] [PubMed]

46. Palombo, E.A. Traditional medicinal plant extracts and natural products with activity against oral bacteria: Potential application in the prevention and treatment of oral diseases. Evid. Based Complementary Altern. Med. 2011, 1-15. [CrossRef]

47. Hwang, J.-T.; Park, Y.-S.; Kim, Y.-S.; Kim, J.-C.; Lim, C.-H. Isolation and identification of antifungal compounds from Reynoutria elliptica. Korean J. Agr. Sci. 2012, 39, 583-589. [CrossRef]

48. International Organization for Standardization. ISO 10993-5: 2009 Biological Evaluation of Medical Devices-Part 5: Tests for in vitro Cytotoxicity; International Organization for Standardization: Geneva, Switzerland, 2009; Available online: https://www.iso.org/standard/36406.html (accessed on 21 May 2020).

49. Kim, J.-E.; Kim, H.-E.; Hwang, J.-K.; Lee, H.-J.; Kwon, H.-K.; Kim, B.-I. Antibacterial characteristics of Curcuma xanthorrhiza extract on Streptococcus mutans biofilm. J. Microbiol. 2008, 46, 228-232. [CrossRef]

50. Mohamed, A.A.; Ali, S.I.; El-Baz, F.K. Antioxidant and antibacterial activities of crude extracts and essential oils of Syzygium cumini leaves. PLoS ONE 2013, 8, e60269. [CrossRef] [PubMed]

51. Ignat, I.; Radu, D.G.; Volf, I.; Pag, A.I.; Popa, V.I. Antioxidant and antibacterial activities of some natural polyphenols. Cytokines 2013, 4, 387-399.

52. Smullen, J.; Koutsou, G.; Foster, H.; Zumbé, A.; Storey, D. The antibacterial activity of plant extracts containing polyphenols against Streptococcus mutans. Caries Res. 2007, 41, 342-349. [CrossRef] [PubMed]

53. Kato, T.; Iijima, H.; Ishihara, K.; Kaneko, T.; Hirai, K.; Naito, Y.; Okuda, K. Antibacterial effects of Listerine on oral bacteria. Bull. Tokyo Dent. Coll. 1990, 31, 301-307. [PubMed]

54. Vlachojannis, C.; Al-Ahmad, A.; Hellwig, E.; Chrubasik, S. Listerine ${ }^{\circledR}$ products: An update on the efficacy and safety. Phytother. Res. 2016, 30,367-373. [CrossRef]

55. Meiller, T.F.; Silva, A.; Ferreira, S.M.; Jabra-Rizk, M.A.; Kelley, J.I.; DePaola, L.G. Efficacy of Listerine ${ }^{\circledR}$ Antiseptic in reducing viral contamination of saliva. J. Clin. Periodontol. 2005, 32, 341-346. [CrossRef] [PubMed]

56. Vlachojannis, C.; Winsauer, H.; Chrubasik, S. Effectiveness and safety of a mouthwash containing essential oil ingredients. Phytother. Res. 2013, 27, 685-691. [CrossRef]

57. Korkmaz, Y.N.; Bulut, M. Effect of mouthwashes on the discoloration of bracket-bonded tooth surfaces: An in vitro study. Clin. Oral Investig. 2020, 1-7. [CrossRef]

58. Lee, J.H.; Kim, S.H.; Yoon, H.I.; Yeo, I.S.L.; Han, J.S. Colour stability and surface properties of high-translucency restorative materials for digital dentistry after simulated oral rinsing. Eur. J. Oral Sci. 2020, 128, 170-180. [CrossRef]

(C) 2020 by the authors. Licensee MDPI, Basel, Switzerland. This article is an open access article distributed under the terms and conditions of the Creative Commons Attribution (CC BY) license (http://creativecommons.org/licenses/by/4.0/). 